\title{
Blaschko linear hyperpigmentation: What is your diagnosis?
}

\section{Selma El Kadiri, Hanane Bay Bay, Rhizlane Chaoui, Zakia Douhi, Sara Elloudi, Fatima Zahra Mernissi}

Department of Dermatology and Venerology, University Hospital Hassan II, Fez, Morocco

Corresponding author: Dr. Selma El Kadiri, E-mail: elkadiri-s@hotmail.com

\section{CASE REPORT}

Linear and whorled nevoid hypermelanosis (LWNH) is a rare disorder of pigmentation characterized by hyperpigmented macules in a linear or whorled streaky distribution [1]. Herein, we report a rare case of LMNH.

A 7-year-old girl was referred by a pediatrician for diffuse hyperpigmentation that had appeared at the age of 2 months on the back. They grew progressively to involve the full body. There was no familial history of pigmentary disorders. Clinical dermatology showed swirls and streaks of brown macules following the lines of Blaschko, involving trunk and limbs (Figs. 1 and 2). The lesions spared the palms, soles, and mucosae. The parents didn't report previous vesicles or verrucous lesions. Systemic examination including neurologic, musculoskeletal, cardiac, and dental didn't show any abnormalities. Histologic examination of biopsy specimens revealed basal cell layer hyperpigmented with an increase in the density of melanocytes. There were only a few melanophages. Ophthalmologic examination was normal.

\section{What's your diagnosis?}

Answer: Linear and whorled nevoid hypermelanosis

Linear and whorled nevoid hypermelanosis is a rare sporadic disorder with no gender predominance [1]. They are other synonyms in the literature: Linear nevoid hyperpigmentation, reticulate hyperpigmentation of Iijima, Naito, and Uyeno, and zebra-like hyperpigmentation in whorls and streaks [2]. It is characterized by whorls and streaks following the lines of Blaschko starting within the first year of life and extends to the full body at the 2-3 years of age. LWNH is

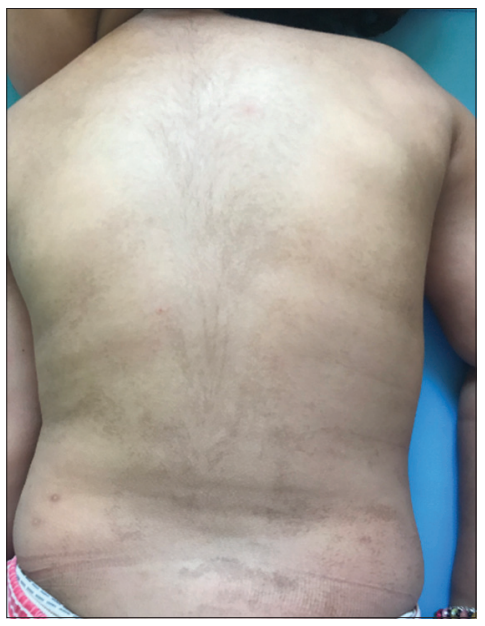

Figure 1: Linear and whorled nevoid hypermelanosis on the trunk.

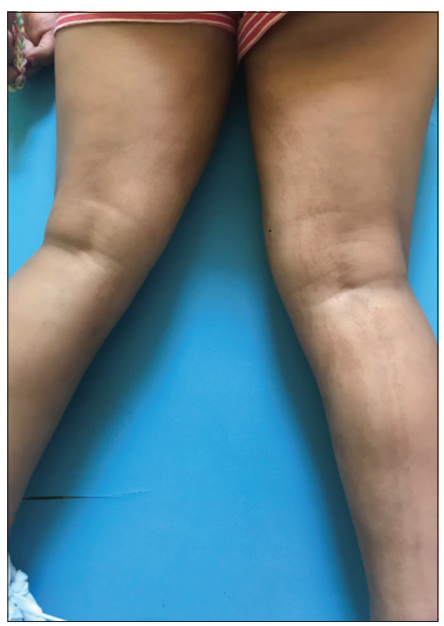

Figure 2: Hyperpigmented macules in a linear or whorled streaky distribution in the limbs.

a heterogenous mosaic skin condition of a clone of skin cells with increased pigment production [1]. In 10-25\% of patients, there are neurologic, musculoskeletal, or

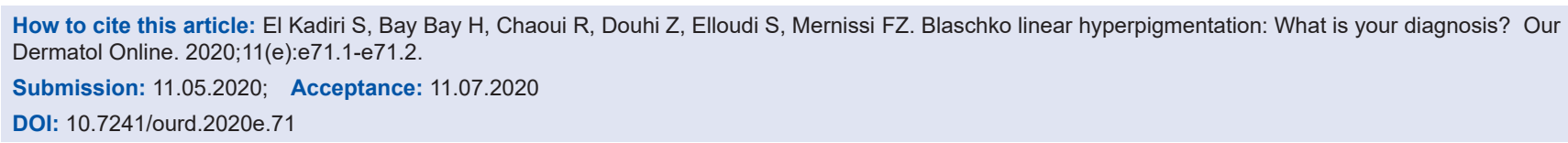


cardiac abnormalities. Histology is characterized by basal cell layer melanin with an increase in the density of melanocytes and few melanophages. LWNH can be confused with other diseases that follow lines of Blaschko such as incontinencia pigmenti in the 3rd stage which is characterized by previous vesicular and verrucous stage, a grayish-brown color and more melanophages in the dermis [3]. Rarely hypohidrosis ectodermal dysplasia, Conradi-Hünermann-Happle syndrome, café-au-lait macules of McCune-Albright syndrome can be confusing disorders with early-onset and hyperpigmentation following lines of Blaschko. There is no current treatment of LWNH, but camouflage cosmetics may be helpful [4].

\section{Consent}

The examination of the patient was conducted according to the Declaration of Helsinki principles.

The authors certify that they have obtained all appropriate patient consent forms. In the form the patient(s) has/have given his/her/their consent for his/her/their images and other clinical information to be reported in the journal. The patients understand that their names and initials will not be published and due efforts will be made to conceal their identity, but anonymity cannot be guaranteed.

\section{REFERENCES}

1. Yao L, Zhou DD, Lu CW. Linear and Whorled Nevoid Hypermelanosis. Am J Med Sci. 2017;353:e1.

2. Pinheiro A, Mathew MC, Thomas M, Jacob M, Srivastava VM, Cherian R, et al. The clinical profile of children in India with pigmentary anomalies along the lines of Blaschko and central nervous system manifestations. Pediatr Dermatol. 2007;24:11-7.

3. Malakar S, Mukherjee SS. Dermosccopic features of progressive cribriform and zosteriform hyperpigmentation. Our Dermatol Online. 2018;9:343-5.

4. Syed MMA, Amatya B, Parween S. Hypohydrotic ectodermal dysplasia: a case report. Our Dermatol Online. 2018;9:464-5.

Copyright by Selma El Kadiri, et al. This is an open access article distributed under the terms of the Creative Commons Attribution License, which permits unrestricted use, distribution, and reproduction in any

medium, provided the original author and source are credited.

Source of Support: Nil, Conflict of Interest: None declared. 